\title{
LIBERALISMO Y FEMINISMO: UN ANÁLISIS AUSTRIACO
}

\author{
CRISTINA LOZANO GONZÁLEZ*
}

Fecha de recepción: 18 de febrero de 2013.

Fecha de aceptación: 25 de junio de 2013.

Resumen: En este artículo se explica brevemente cómo se entrelaza la teoría de la Escuela Austriaca con la teoría feminista, siguiendo, en esta última corriente, a una de sus autoras fundamentales, Betty Friedan. Yendo más allá de las interpretaciones típicas sobre el movimiento feminista como una ideología de izquierdas, se resalta la importancia del papel del derecho a la propiedad privada en el desarrollo de sus propuestas y la necesidad de que exista libertad económica para fomentar la riqueza de toda la ciudadanía.

Palabras clave: Estado, Libertad, Igualdad, Capitalismo, Derecho, Educación, Propiedad Privada, Feminismo, Avance Social, Justicia.

Clasificación JEL: P1.

Abstract: This article briefly explains how the theory of the Austrian School and the Feminist Theory intertwine following, in this last theory, one of the fundamental authors, Betty Friedan. Beyond the typical interpretations about the feminist movement as a left-wing ideology, it is underlined, the importance of the role in the right to the private property concerning the development of its proposals and the need that economic freedom exists to promote the wealthness to all the citizens.

Key words: State, Freedom, Equality, Capitalism, Right, Education, Private Property, Feminism, Evolution of Society, Justice.

JEL Classification: $\mathrm{P} 1$.

* Filósofa y economista.

Procesos de Mercado: Revista Europea de Economía Política Vol. X, n.․․ 2, Otoño 2013, pp. 39 a 72 


\section{INTRODUCCIÓN}

Habitualmente, se suele asociar la teoría feminista con movimientos de corte izquierdistas. ¿Hasta qué punto es cierta esta idea? En los orígenes del movimiento feminista, las primeras mujeres que se podían llamar «feministas», aunque sea vagamente, fueron monjas (que eran las únicas que sabían leer y escribir). Y en el primer movimiento feminista en sentido estricto, esto es, el sufragismo, llama la atención que lo compusieran, sobre todo, mujeres burguesas, con un alto poder adquisitivo y, por lo tanto, con tiempo y recursos económicos y educativos para dedicarles a esa causa (la consecución del derecho al voto de las mujeres). ¿Sería compatible, entonces, una teoría feminista con, por ejemplo, el libre mercado? Los escritos publicados, normalmente, responden a esta pregunta con un no rotundo, aunque no podemos olvidar a algunas autoras, como Ayn Rand, que defienden los derechos de las mujeres y el sistema capitalista al mismo tiempo.

Por eso, el objetivo de este artículo es esclarecer la información de la teoría feminista y del liberalismo económico, para llegar a una respuesta a la anterior pregunta. Si hay una rama de la teoría feminista que, aunque sea en principio, es compatible con el libre mercado, es el feminismo liberal. Entonces, surge otra cuestión: ¿es cierto que es insostenible el feminismo liberal y que acaba desembocando en feminismo radical? Si la respuesta es un sí, la teoría feminista sería enemiga del libre mercado. Pero si podemos encontrar los argumentos para responder «no», entonces, pueden ser compatibles.

En el siguiente apartado, se realiza una introducción sobre la Escuela Austriaca y el ordoliberalismo, para, posteriormente, exponer en qué consiste exactamente el liberalismo económico. El liberalismo es individualista, igualitario, universalista y meliorista.

A continuación, se explica el individualismo, un pensamiento muy presente en el liberalismo. Es importante resaltar que sus ideales fueron la causa de la creación del socialismo, puesto que se creó como contraposición al primero.

Después, se analiza la obra de una de las teóricas feministas liberales más importantes, a saber: Betty Friedan. Friedan es una 
psicóloga social que entiende que la situación en la que viven las mujeres se debe a la existencia de un marco legal que es necesario modificar para mejorar la calidad de vida de todas las personas, no sólo las mujeres. Así, se resalta la importancia del derecho y la justicia en la teoría feminista, al igual que lo es en la Escuela Austriaca.

Betty Friedan comenzó en su vida del lado comunista pero, como se puede leer en sus obras, repetidamente escribe que continuamente le decepcionaba, que cada vez era menos comunista y que no le convencían ya los ideales que se defendían desde esta corriente ni la dicotomía existente entre sus teorías y la forma de vida real en estas organizaciones. No era cierto lo que afirmaba Marx de que era la clase obrera la única capaz de hacer la revolución, igual que no es negativo reconocer que el movimiento de mujeres lo lideraban mujeres blancas con estudios y pertenecientes a la clase media. ¿Acaso no era eso una revolución por no ser obreras? Para poder dirigir es necesario poseer un mínimo de formación académica. De lo que se trataba, después de todo, era de hacer al feminismo un movimiento lo más amplio posible, independientemente de que hubiera mujeres conservadoras o de izquierdas en él. Friedan quería ampliar el significado de «feminismo». Estudió como había evolucionado el feminismo en los países socialistas, como Finlandia, Suecia y Checoslovaquia. Pero, como dice la autora «una vez más, sufrí una decepción» (Friedan, 2003, p. 265).

Para finalizar con esta introducción, se expone una cita de Betty Friedan en la que define lo que es el movimiento feminista y con la que se descarta cualquier malinterpretación de este movimiento social:

La ideología de las personas que iniciamos el movimiento de mujeres no era sexual ni política. Entonces habría dicho que no teníamos ideología. No había más que la idea de igualdad, de democracia norteamericana. Pero cuando fueron unas mujeres las que la aplicaron a las mujeres, desde la perspectiva del coraje y de la sustancia de sus propias vidas y de sus deberes cotidianos en cuanto mujeres, se convirtió en una revolución completamente distinta de todas las anteriores. No se trataba en absoluto de un grupo oprimido que se hace con el poder y se dedica a oprimir a sus antiguos opresores. Aquello era una revolución y un concepto totalmente nuevo: un movimiento de mujeres que luchaba por la 
igualdad en una asociación auténticamente igualitaria con los hombres (Friedan, 2003, p. 251).

\section{II}

\section{ESCUELA AUSTRIACA Y ORDOLIBERALISMO}

A partir de los años 30 del siglo XX el modelo de equilibrio sintió todo el protagonismo y fue el centro de los estudios de economía. Las tres décadas siguientes a la Segunda Guerra Mundial (hasta 1975) todos los economistas siguen en la economía occidental la teoría de Keynes, el ordoliberalismo y el sistema neoclásico. No obstante, no es suficiente con decir que como la planificación ha resultado eficaz en tiempos de guerra también hay que aplicarla en la paz. Ciertas medidas intervencionistas que en tiempos de paz se hubieran calificado de inadmisibles en la guerra funcionaron relativamente. Por eso es asombroso que después de la guerra se mantuvieran esas políticas intervencionistas. Además, esta época intervencionista coincide con la vuelta en Norteamérica de la mística de la feminidad, como se analizará posteriormente. ¿Se podrá tratar de simple coincidencia o dicha mística es debida a una intervención estatal tan elevada? El Estado realiza funciones muy importantes (leyes, calles, seguridad, carreteras...) pero eso no significa que él sea el único capaz de hacerlo, ni que desarrolle dichas tareas correctamente.

Dentro de las tesis del equilibrio, se encuentran dos grupos: (1) La Escuela Neoclásica, y (2) La Escuela de Chicago.

- Escuela Neoclásica, formada por Samuelson (y junto a él Kenneth Arrow, Gerard Debreu, Frank Hahn y Joseph Stiglitz entre otros). Según ellos, cuando se percate de que existe un desajuste de la realidad al equilibrio en competencia perfecta, el Estado debe intervenir en dicho fallo del mercado para acercar la realidad al equilibrio.

En la actualidad se está notando un nuevo y gran impulso de la Escuela Austriaca (Hayek, Mises, Kirzner...) proveniente de jóvenes estudiantes tanto de Estados Unidos como de Europa y que critican frontalmente a los neoclásicos. La caída del muro de Berlín 
$y$, gracias a ello, del llamado socialismo real ha generado que el modelo económico cambie y ya no sea tan protagonista el modelo neoclásico. Lo positivo es que no se parte de cero para cambiar la economía, sino que se cuentan con muchos estudios de los que partir a través de los textos de la Escuela Austriaca.

Mises defiende que la insatisfacción humana es lo que previene a la acción, ya que es la que empuja a la persona a actuar. Además, también expresa que dicha acción es la única manera que tiene el ser humano de defenderse de la naturaleza.

A los austriacos les da tristeza pensar en las consecuencias psicológicas del keynesianismo, ya que ha provocado una mentalidad bien arraigada en la comodidad de delegar en los burócratas todas las cuestiones. Es un pensamiento muy complicado de modificar. En resumen, para la Escuela Austriaca el Estado comunista comete dos errores: malcría a sus ciudadanos educándolos en la pasividad y dependencia y, además, los empuja a organizarse mafiosamente fuera del Estado, como se verá con mayor profundidad más adelante).

Por otro lado, también se le critica a Keynes su falta de formación (Hayek por ejemplo manifiesta que Keynes básicamente sólo había estudiado a Alfred Marshall). Pero no es sólo eso, sino que él mismo lo reconoce cuando afirmó que no había podido entender bien la obra de Mises en su Treatise on Money debido a que no sabe hablar alemán. Hayek también escribe que las medidas keynesianas provocan grandes problemas a medio/largo plazo y dificultan la coordinación en el mercado.

— Escuela de Chicago. Éstos son más partidarios de la economía de mercado que los neoclásicos, aunque también defienden un equilibrio de mercado. Algunos de sus componentes son: Milton Friedman, George Stigler, Robert Lucas, Gary Becker ${ }^{1} \ldots$

1 Para Becker la cuestión realmente importante en la economía es la de la toma de decisiones. Por eso, Becker se basa en tres hipótesis: «maximización de la función de utilidad ampliada, equilibrio de mercado y preferencias estables a lo largo del tiempo de las mercancías que entran como argumentos de la función de utilidad ampliada» (Aranzadi del Cerro, 1999, p. 182). Según el autor, el comportamiento económico apunta al futuro y se da por hecho que es estable conforme pasa el tiempo. Becker usa la metodología de Friedman para ampliar la teoría neoclásica. 
No obstante, la Escuela Austriaca y la Escuela de Chicago no son siquiera parecidas. Mientras que la primera apuesta por pensar su teoría de la acción desde la capacidad de crear del ser humano, la segunda simplifica el comportamiento humano a comportamiento monetizable. Es decir, la primera es un liberalismo humanista y la segunda un humanismo tecnicista.

Pero este análisis quedaría incompleto si no se tuviera en cuenta el ordoliberalismo, teoría que intenta mejorar el liberalismo. Dentro de los ordoliberales cabría destacar a Ludwing Erhard, Wilhelm Röpke y a Leonhard Miksch. El estudio central del ordoliberalismo es la crisis de su tiempo, definida como: «la crisis mundial de nuestros días es el resultado final de una evolución política y espiritual, cuyos comienzos se remontan al Renacimiento, pero que sólo ha ido perfilándose con toda nitidez en el transcurso de los dos últimos siglos, el XVIII y el XIX, hasta llevarnos al punto en que hoy nos encontramos» (Röpke, 2010, p. 131)... «Ambas revoluciones, la política y la económica, están íntimamente relacionadas, como es natural, y tienen su origen común en el alma social tal y como la ha ido configurando el movimiento de emancipación espiritual de la Edad Moderna» (Röpke, 2010, p. 132). De esta manera, todo el ordoliberalismo se posiciona en el intento de diagnosticar y solucionar "la crisis social de nuestro tiempo" (Böhmler, 1998, p. 289), entendiendo que están en el momento en el que hay que inventar una nueva forma de política económica que no sea como los métodos conocido.

Para los ordoliberales, se dan dos ideologías: el capitalismo (que pretende el máximo bienestar de la mayor parte de la gente a través de la libertad económica y el estado de derecho), y el socialismo (que procura la libertad a través de la total igualdad y la colectivización de la propiedad). El ordoliberalismo, de creación alemana, es importante para esa decisión que parece obligada únicamente entre capitalismo y socialismo. De esta manera, esta nueva corriente se propone como una «tercera vía» que ha adquirido mayor relevancia en el sector empresarial que en cualquier otro. Pero, aunque esas ideas se crearon con el objeto de ofrecer una nueva salida a la polaridad entre capitalismo y socialismo y los ordoliberales hablan de una tercera vía saben que no es así, ya que como, según ellos, el colectivismo no es una alternativa, 
no existe una segunda vía al liberalismo, y si no existe la segunda, mucho menos la tercera.

Realizada ya esta presentación, se pasará a explicar más en profundidad cada una de ellas, comparándolas y contraponiendo unas con otras.

Mises entiende la función empresarial como capacidad innata en el ser humano para crear y percatarse de las oportunidades que surgen y aprovecharlas. Por eso, todas las acciones tienen un carácter empresarial. La habilidad empresarial del ser humano implica que éste esté continuamente creando y buscando información y que se coordine en el mercado de una manera espontánea, siempre que no exista coacción. La clave en la teoría austriaca es la función empresarial, contraria al equilibrio y ausente en la teoría neoclásica. La función del empresario es crear y descubrir información. Hasta que éste no la crea no existe, por lo que no es posible decidir al modo neoclásico sobre la asignación de beneficios y costes estimados. Para la Escuela Austriaca, la economía siempre se sustenta en el ser humano entendiéndole como creativo y protagonista. Tanto la creación como la evolución de las instituciones sociales son entendidas desde el subjetivismo y la espontaneidad.

La cuestión, por tanto, para los austriacos es muy diferente de la de los neoclásicos: la coordinación social de la información que crean los empresarios y que nunca está dada. Para los neoclásicos, como la información está dada, la cuestión es técnica, al estar la información dada y únicamente tener que preocuparse por la optimización. Además, las matemáticas no sirven en la economía, ya que un cliente puede preferir A a B, y B a C, pero ese mismo cliente puede preferir $\mathrm{C}$ a $\mathrm{A}$. Los teóricos austriacos opinan que el ser humano consta de una congénita habilidad empresarial creativa, siendo así la clave la creatividad. De esta manera, las estadísticas no aportan ninguna información, contrariamente a como opinan los neoclásicos.

La concepción de la Escuela Austriaca entiende que el ser humano no asigna medios dados a fines dados, sino que los busca. Aprende del pasado, crea, descubre... por eso, para ellos, la economía está dentro de la teoría de la acción humana. El ser humano es, pues, un actor creativo y protagonista. Como el origen del 
conocimiento se encuentra en la capacidad creativa del ser humano, cualquier sistema que se base en la coacción (como socialismo o intervencionismo) imposibilita dicha creación de conocimiento. La función empresarial coincide con la acción humana, como ya se ha comentado. Los empresarios crean continuamente información de carácter subjetivo, práctico, disperso y laboriosamente articulable. ${ }^{2}$

Röpke analiza qué características tiene que tener un Estado sano. Un Estado enfermo es aquél que pretende intervenir en todas las áreas del individuo, lo que conlleva, como se ha visto, corrupción y eliminación de la religión. Para sanear este Estado habría que llevar a cabo una separación de poderes, la famosa idea de Montesquieu. El Estado sano cuenta con legitimidad, libertad y descentralización. La legitimación conlleva liberalidad y descentralización. El Estado sano sabe compatibilizar libertad y orden. Su idea de Estado fuerte no es uno que intervenga en todo, sino un Estado que tenga la fortaleza de gobernar y estar por encima de los grupos de interés. La tarea política debe desarrollarse conforme a la idea de sobriedad, integridad, concisión y realismo. No obstante, el Estado de derecho se encuentra socavado debido a la falta de democracia liberal y excesiva democracia jacobina igualitaria.

Los ordoliberales abogan por una economía de mercado debido a su idea de Estado y libertad. Por eso, no se pueden separar el liberalismo económico del político. Röpke advierte señalando también que esta idea ha sido trabajada anteriormente por Benjamín Constant y John Stuart Mill, el peligro de la mayoría en la democracia, si se entiende como la dictadura de la mayoría. Röpke critica que se ha seguido demasiado a Rousseau y Voltaire y muy poco a Montesquieu. Röpke es anticomunista y también habla del declive de la familia.

El capitalista facilita la vida de los trabajadores, ya que gracias a su ahorro a través de la renuncia al consumo durante algún tiempo determinado puede adelantar el sueldo a sus empleados,

2 Por eso, mientras que para los austriacos la información tiene un carácter subjetivo, para los neoclásicos ésta es objetiva (se puede vender y comprar como las mercancías). 
permitiéndoles seguir consumiendo sin tener que reducir sus gastos ni ampliar sus ahorros. El capitalista ha trabajado y ha limitado su consumo para poder ahorrar. Después, con contratos voluntarios compra derechos de propiedad de bienes de capital y paga a sus trabajadores. Es decir, no es que el capitalista se aproveche del trabajador. Más bien, ocurre todo lo contrario: posibilita el dinero de su trabajo al empleado antes de que se venda el producto o servicio. Además, elimina el riesgo que sufre él a los trabajadores por si, al final, no se vendiera el producto al precio esperado.

Otra cuestión que no puede pasar por alto en este análisis es el debate sobre la imposibilidad teórica o no del socialismo. Desde el punto de vista de la Escuela Austriaca el socialismo es imposible por las siguientes cuatro razones:

1. Existe una gran cantidad de información.

2. La información es diseminada, subjetiva y tácita.

3. Como los empresarios son los que generan la información, no se puede transmitir hasta que no existe.

4. La coacción distorsiona la creación de información.

Los teóricos neoclásicos socialistas no entendían la imposibilidad del socialismo ya que parten de la base de que toda la información está dada. Pero, en la realidad, la información nunca está dada, sino que son los empresarios la que la descubren y crean continuamente. La competencia se basa en el descubrimiento de información. Para la Escuela Austriaca la información es algo subjetivo y nunca está dada, ya que es generada continuamente por los empresarios cuando perciben una posible situación de ganancia.

Como el origen del conocimiento se encuentra en la capacidad creativa del ser humano, cualquier sistema que se base en la coacción (como socialismo o intervencionismo) imposibilita dicha creación de conocimiento. Se basa en que el órgano director al emitir sus mandatos sobre un determinado proyecto no dispone de la información necesaria, por lo que no puede conocer si está actuando adecuadamente. Si se parte de la base de que el órgano director posee toda la información y que, además, ésta no cambia, no habría este problema. El ser humano sufre gran incertidumbre hacia los hechos futuros que no puede eliminar, sino sólo reducir 
a través del conocimiento bien desarrollado de teoría y mucha experiencia sobre los juicios de valor y la motivación que ha llevado a actuar a los seres humanos de determinada manera. Algunas personas son más capaces que otras de planificar su futuro. El empresario es el que actúa pensando en cómo será el futuro. Por eso todos somos empresarios, porque todos tomamos decisiones en función de cómo creemos que va a ser el futuro. Pero es importante insistir en la idea de que ningún economista puede predecirlo.

Lo más importante para la Escuela Austriaca, no es quiénes sean los empresarios, sino que exista total libertad empresarial para que cada persona pueda sacar lo máximo de su información. Por eso, los teóricos de la Escuela Austriaca son filósofos liberales que defienden el libre mercado. Son contrarios al socialismo, además, ya que como éste se basa en la coacción, hace desaparecer la ley (aplicada a todos por igual...), quedando ésta sustituida por los mandatos del órgano director (independientemente de si se ha establecido democráticamente o no). ${ }^{3}$

Se suelen realizar siete críticas a la Escuela Austriaca:

1. La teoría de la Escuela Austriaca y la neoclásica no son incompatibles, sino complementarias.

A esto los teóricos austriacos argumentan que es una manera de justificarse para hacer débiles las críticas vertidas por ellos a los neoclásicos.

2. Los austriacos no deberían criticar a los neoclásicos por simplificar los supuestos que facilitan la comprensión de la realidad.

Los austriacos se defienden afirmando que no es lo mismo un supuesto simplificado que uno irreal. Lo que ellos critican de los neoclásicos no es que usen supuestos simplificados, sino irreales.

${ }^{3}$ Así, el socialismo fomenta el incumplimiento de la ley: a veces por pura supervivencia y otras veces debido a una función empresarial corrupta. En cualquier caso, la ciudadanía pasa a juzgar esta actitud como un símbolo de ingenio humano. Por esto, la justicia también queda trastocada. Tradicionalmente, se ha entendido la justicia como neutral, igual para todos y siempre se le ha representado con los ojos tapados, ya que tiene que ser ciega, siéndole indiferente a quién esté juzgando. En el socialismo se desvirtúa esta visión de la justicia y el órgano director la aplica caprichosamente, no juzgándose ya el hecho, sino el resultado final de la acción. 
3. Los teóricos austriacos no aciertan al ofrecer una alternativa teórica.

A esto responden con la simple idea de que el uso del formalismo matemático es un error, no una habilidad. El lenguaje científico correcto es el que desarrollan espontáneamente los individuos.

4. Los trabajos empíricos de los austriacos escasean.

Los austriacos reconocen la relevancia de la historia, pero su actividad científica la desarrollan en la teoría. Defienden que hay demasiados estudios empíricos pero muy pocos teóricos.

5. Los austriacos rechazan la predicción económica.

La Escuela Austriaca es humilde en cuanto a las predicciones económicas. Por eso, se preocupan más de estudiar las leyes teóricas que den paso a que los actores puedan analizar la actualidad y decidir con más posibilidad de acierto.

6. Los austriacos no cuentan con criterios empíricos para corroborar sus teorías.

Según estos críticos, el único camino para demostrar que una teoría es correcta es acudiendo a la realidad empírica. Los austriacos opinan, sin embargo, que las teorías se pueden validar por la continua corrección de sus errores en su razonamiento lógico-deductivo. La clave son el análisis y la revisión.

7. Atribución de dogmatismo a la Escuela Austriaca.

Los austriacos contra argumentan que, precisamente, los arrogantes y los dogmáticos son los neoclásicos, ya que centran todo en la cuestión del equilibrio, creyéndose que poseen el monopolio de «lo económico», ignorando las alternativas que les ofrecen otras teorías, como la austriaca.

Siguiendo con las críticas al liberalismo, se debe destacar la idea de Rüstow cuando señala que son dos los motivos por los que el liberalismo económico ha fallado, a saber: su ceguera sociológica y su dogmatización. Esta ceguera es la que Rüstow y Röpke pretenden solucionar a través de su liberalismo revisionista sociológico. El hecho de denominarse Röpke revisionista indica su prudencia y humildad, ya que entiende que la única vía para avanzar es la continua auto-corrección. Para Röpke, el ordoliberalismo no es un punto y aparte de la tradición liberal anterior, sino un 
continuador y restaurador. La «reforma» es algo íntimamente unido a la humanidad. Todas las organizaciones se encuentran en la obligación de rehacerse continuamente. Los ordoliberales comparten con los neoliberales austriacos una idea, a saber: la razón humana tiene límites. Por ello, se hacen eco también de su defensa de un orden espontáneo.

Al mismo tiempo, apunta a la idea de que los individuos compiten en la sociedad, no como Robin Hood que roba a los ricos para dárselo a los pobres, sino que cada individuo intenta conseguir el máximo beneficio posible a sus grupos aliados y así ganar votos de cara a las siguientes elecciones. Las ayudas estatales muchas veces frenan esa carrera y ese ímpetu por conseguir mejores cosas y las ganas de trabajar, cosa que a pequeña escala podría seguir haciendo la familia. Pero al intervenir así el Estado se suben los impuestos, se genera inflación etc. Por eso, hay que rechazar el colectivismo y defender el liberalismo pero no el del siglo XIX sino un liberalismo más fresco. En el capitalismo los beneficios pueden ser muy grandes, pero también las pérdidas. De este modo, se van eligiendo a los directores del proceso de producción. El socialismo tendría que crear otro sistema que recompensara los aciertos y castigara los errores diferentes al capitalista. Hasta hoy, a nadie se le ha ocurrido. El ordoliberalismo lucha contra el colectivismo y propone una revisión del liberalismo. Como hay dos frentes abiertos, se trata de una lucha muy dura, que necesita "gran capacidad combativa, espiritual y moral» (Böhmler, 1998, p. 50).

Röpke se preguntó: «¿de qué sirve todo bienestar material si simultáneamente hacemos que el mundo sea cada vez más feo, más ruidoso, más vulgar y aburrido y si los hombres pierden el fundamento intelectual y moral de su existencia?» (Böhmler, 1998, p. 269). El problema es que el nihilismo se ha ido extendiendo como la espuma y ha conllevado a que el hombre «masa» no se pueda percatar de las «esencialidades» de la vida. La solución de la crisis no se encuentra en el campo económico, sino en el ordenamiento societario y sus valores.

El humanismo económico, esto es, la tercera vía, se basa en la desproletarización del ser humano, y la desmasificación y descentralización de la sociedad. Es una conjunción de ordoliberalismo y humanismo. El ordoliberalismo se basaría en la libertad, y el 
humanismo en el carácter más ético. El liberalismo del autor defiende una herencia del verdadero cristianismo. De este modo, también resalta sus raíces en la cultura jónica, la Estoa Romana y la Escolástica tomista. La concepción ordoliberal del ser humano se aleja del colectivismo y queda impregnada de humanismo cristiano. Röpke opinaba que, aunque solamente Dios conoce el futuro y el resultado final de todas las cosas, nuestra obligación es cumplir sus mandamientos y aprovechar nuestras habilidades. La ética es necesaria para que la competencia no acabe en guerra civil, ya que la política no es suficiente para evitarla. El autor señala que con la guerra se ha aprendido lo importante que es la libertad y por eso triunfa el antimilitarismo. La ética ordoliberal cuenta con una esfera religiosa y otra ilustrada. Tanto la eficacia como la moralidad son aspectos indispensables de la economía. Según los ordoliberales, los problemas del mercado no se solucionan con intervencionismo, con impuestos y ayudas económicas, sino con una actuación moral de los seres humanos. Opinan que su sociedad está masificada. ${ }^{4}$ En una sociedad masificada tanto los valores éticos como espirituales se encuentran ausentes en la política. Y la política queda simplificada al ámbito económico. Pero, Según Röpke la libertad económica y la libertad política van unidas. Por eso rechaza que el Estado centralice todo.

III

\section{LIBERALISMO}

Lo que se entiende por «liberalismo» se ha ido transformando desde sus orígenes en la Inglaterra del siglo XVII, aunque no ha sufrido cambios tan trascendentales como para no reconocerse en absoluto en las ideas en las que se originó. Lo importante cuenta con una definición del ser humano y de la sociedad que se mantiene

4 La entrada en la escena política de las masas populares es analizada en la obra La rebelión de las masas de Ortega y Gasset. El hombre-masa, mediocre y satisfecho de su mediocridad cree que sólo tiene derechos y carece de obligaciones. Se padece un profundo estado de desvertebración que confluye en el triunfo de particularismos enfrentados y de separatismos desintegradores. 
a lo largo de todos estos siglos. A saber: esta concepción es individualista (ya que otorga mayor importancia a las personas frente a las colectividades), igualitaria (porque entiende en todos los seres humanos la misma categoría moral), universalista (al defender una unidad moral para todos los seres humanos) y meliorista (en tanto que opina que todas las instituciones sociales y pactos políticos son mejorables).

Los conceptos de ciudadano y propiedad privada son los que mejor muestran el desarrollo y evolución del liberalismo desde sus comienzos (Hobbes) hasta la actualidad (Popper, Hayek...). Ha ido ensanchándose el concepto de ciudadano, mientras que el de propiedad privada ha sufrido también grandes cambios. Al principio, se encontraban tan relacionados que el criterio para ser ciudadano era la posesión de propiedad privada. No obstante, gracias, entre otras, a las luchas feministas, se ha ampliado el concepto de ciudadano y su criterio ya no es el de la propiedad privada. De esta manera, aunque la propiedad privada sigue siendo fundamental en el liberalismo, no tiene consecuencias teóricas sobre los derechos políticos formales.

Las aportaciones de pensadores como Bentham (en contraposición a John Stuart Mill), eran reacias a aprobar un sufragio plenamente universal, al encontrar adecuado excluir del derecho al voto a los pobres, analfabetos, dependientes y a las mujeres. Sin embargo, con los cambios que se han ido produciendo en los principios y marcos de las democracias liberales, ha sido posible introducir en ellos una perspectiva más igualitaria que extendiera los votos a un mayor número de personas, independientemente de sus condiciones económicas, sexo, raza y religión.

Los liberales son partidarios de los gobiernos limitados, pero no por ello de los gobiernos mínimos. De esta manera, defienden que el gobierno puede prestar distintos servicios más allá de la protección de los derechos y de la justicia. Un gobierno ilimitado nunca es liberal, al ser totalitario, pero un Estado liberal puede realizar funciones de carácter positivo con el objetivo de asegurar la libertad (como medidas para evitar los monopolios y defensa del consumidor). Así, además, se evitan las ideas anarquistas y se entiende al Estado como un mal necesario. Si el gobierno tiene poder sobre los medios económicos, también lo tendrá sobre 
los fines que perseguimos en la vida. Por ejemplo, es difícil que exista libertad de prensa si las editoriales son sólo propiedad del gobierno, o libertad de libre asociación si los locales en los que se puede reunir la gente son sólo del gobierno...y así un largo etc. Es decir, sólo podremos perseguir nuestros propios fines si tenemos varios medios distintos para conseguirlos. Hay que prestar libertad a las personas para establecer sus propios fines y los medios para lograrlos.

Las tres ideas básicas de una sociedad liberal son la paz, la justicia y la libertad. El liberalismo hace hincapié en la justicia conmutativa y no en la distributiva o social, que sería la socialista. Como el individuo es libre para decidir corre un riesgo que va anexo no a la bondad o maldad de su decisión, sino al resultado de la misma. Por lo tanto, esta libertad individual es incompatible con la justicia distributiva. El liberalismo aboga por un sistema de recaudación fiscal proporcional en lugar de uno progresista. De esta manera, se eliminaría la arbitrariedad de la política pública, evitándose la eliminación encubierta de la libertad económica. Desde el liberalismo se rechaza tanto la distribución feudal-aristotélica que afirma que hay que repartir según el rango social, como la distribución comunista, donde se reparte según las necesidades y se recibe de cada individuo según sus capacidades, lo cual implica una igualdad universal y material. El criterio liberal defiende que hay que dar a cada uno según su mérito o esfuerzo, es decir, es universal, pero también formal, lo que hace compatible con la desigualdad material.

La igualdad que define el liberalismo es la siguiente: todos los individuos son iguales ante la ley. Ahora bien, si a través de su trabajo y esfuerzo (o, incluso, suerte) destacan, ascienden socialmente y provocan desigualdad material, el Estado no tiene potestad para impedirlo, puesto que, además, siempre permanecerá la igualdad formal.

Para el liberalismo, es necesario que el poder, aunque cuente con el beneplácito de la mayoría, esté sometido a unos límites. Para la democracia, sin embargo, el poder de los límites del gobierno es el de la mayoría. Por lo tanto, el liberalismo es incompatible con la democracia ilimitada y con cualquier tipo de gobierno absoluto. El individualismo no opina que lo que afirma 
la mayoría hoy tenga que ser vinculante para un futuro ya que, precisamente, la Democracia se basa en que lo que hoy defiende una minoría en un futuro puede ser reclamado por la mayoría. Según Hayek, habría que dejar decidir a veces también a la minoría y no siempre a la mayoría. Sobre todo cuando se trata de temas económicos, ya que la decisión de la mayoría va a ser, casi siempre, reaccionario. La libre competencia debe otorgar a la minoría la posibilidad de tener poder de decisión y convertirse, así, en dominante.

Desde el liberalismo, se entiende al Estado como oposición al Estado de bienestar y como un Estado con las mínimas atribuciones posibles y sometido a la ley. Frente al Estado se encuentra el individuo, y su relación queda regulada con la ley. Tanto el Estado como el individuo deben obedecer la ley, pero el Estado protege la ley, es la autoridad para los que no la cumplan. $\mathrm{Si}$ el gobierno asume tareas y responsabilidades que no pueden dirigirse según la mayoría, se tendrán que crear cuerpos especiales para llevarlas a cabo. Cuerpos que, cada vez, serán más totalitarios. Por lo tanto, es pensable que una democracia no liberal acabe dejando de ser democracia. El liberalismo aboga por un "gobierno de la ley» mediante el que la coacción del gobierno se basa y limita en las normas jurídicas generales y universales. Lo negativo es una sobrecarga de las expectativas del poder del Estado lo que conlleva, a su vez, a una sobre-extensión de la participación democrática, lo cual es incompatible con una Democracia supeditada a la ley. Son perjudiciales las democracias ilimitadas porque nadie tiene el poder de actuar siempre correctamente, nadie es perfecto. Hay que ser demócrata, pero no preocuparse tanto por quién gobierna como por limitar su poder.

IV

INDIVIDUALISMO

El término «Individualisme» fue utilizado por primera vez por los discípulos de Claude-Henri de Saint-Simon, alrededor del año 1820. Pero, como escribió Max Weber, el individualismo es una 
corriente que ha tenido muchos significados y que necesita ser estudiada a conciencia.

Un uso del término «individualismo» lo encontramos en la idea romántica alemana de autorrealización, originalidad y unicidad. En Francia se entendía el individualismo como algo negativo, pero en Alemania como algo positivo. Mientras tanto, en los Estados Unidos, individualismo se relaciona con capitalismo y democracia liberal. Se suele decir que el individualismo fue la identidad nacional de los Estados Unidos, pero no sólo eso, sino que también se puede afirmar que la falta de una tradición socialista fuerte en los Estados Unidos es debido, en gran parte, a la influencia del individualismo. Según este punto de vista, el capitalismo implica libertad, ya que supone una ausencia de la coacción. No se entiende desde el punto de vista de Hayek como un punto de encuentro de intereses y conflictos. Y es que, según Hayek, el capitalismo es imprescindible para que se dé la democracia. La clave está en la competencia y en la libre disposición de la propiedad privada. Han comprendido el individualismo como algo positivo personalidades como Theodore Roosevelt. También se entendió el individualismo como una corriente que fomenta la competencia. En la Depresión de $1928^{5}$ el término sufrió una caída de popularidad que pronto remontaría. Así lo demuestra, por ejemplo, el éxito de una mujer, Ayn Rand, que defendió el individualismo, la razón y el capitalismo.

Para aclarar lo que significa «individualismo» es importante resaltar que sus ideales fueron la causa de la creación del socialismo, puesto que nació como contraposición al primero. Los teóricos fundamentales del individualismo han sido John Locke, Bernard de Mandeville, David Hume, Josiah Tucker, Adam Fegurson, Adam Smith y Edmund Burke. Para Smith y sus contemporáneos la preocupación básica no era lo que el ser humano podía mejorar, sino limitar las ocasiones en las que podría actuar mal. Su objetivo era minimizar el daño que pueden causar las personas malas. En la segunda mitad del siglo XIX, «individualismo» se utilizaba como lo contrario a socialismo, comunismo y colectivismo.

${ }^{5}$ Realmente, la crisis del 29 nació en el verano del 28 con el estallido de la burbuja inmobiliaria en Florida. 
El verdadero individualismo supone humildad y respeto hacia los avances que hemos logrado sin que ninguna mente lo haya planificado y que son más importantes que los que hubiéramos conseguido a través de las mentes individuales.

Podríamos resumir la diferencia entre el verdadero individualismo y el falso diciendo que mientras el primero encuentra falible a la razón (defiende sus límites), el segundo abusa de ella. La razón sólo nos ha guiado en parte para lograr las instituciones con las que contamos en la actualidad. El verdadero individualismo es la única corriente que puede afirmar la creación de productos sociales espontáneos. Las teorías que defienden que instituciones...son creadas en su totalidad por la razón y, por lo tanto, requieren un control... acaban siendo socialistas. En contraposición a esto, el verdadero individualismo cree firmemente que si se otorga libertad a los seres humanos gozaremos de mayores avances.

El individualismo no cree que todos los seres humanos contemos con las mismas habilidades y capacidades, pero sí que ningún ser humano está en la situación de definir cuáles son las capacidades de los demás. No existe nadie con esta capacidad y no se le puede permitir a nadie hacer algo así. Como todos los seres humanos son diferentes, la consecuencia es que se les debe tratar por igual. Si todos los seres humanos fueran iguales habría que tratarles de una manera diferente para poder conseguir algún tipo de organización. Como todos somos distintos, cada uno tiene que buscar su papel, y no dejar esta decisión a manos de una institución organizadora. No es lo mismo tratar a las personas de la misma manera que hacerlas iguales. Lo primero es esencial para una sociedad libre, pero lo segundo desemboca en servidumbre. Además, el libre mercado es esencial para que se pueda dar una sociedad libre. La economía de la Escuela Austriaca se basa en que existe un conocimiento que nadie puede poseer completamente. Sólo mediante el mercado unos satisfacen las necesidades de otras personas que ni siquiera conocen. No existen datos definidos que todos conocen. Por eso no se puede planificar.

Desde el punto de vista del liberalismo clásico, la libertad individual necesita la propiedad privada y el libre mercado. Por otro lado, marxistas y socialistas opinan que la propiedad privada 
impide la libertad. Y, por último, liberales revisionistas afirman que, en algunas ocasiones, los derechos de propiedad deben situarse por debajo de otros derechos. El individualismo económico defiende la libertad económica. No es que el individualismo no tenga objetivos sociales a diferencia del socialismo, sino que son otros sus objetivos. El individualismo busca el progreso social mediante el individuo, otorgándole la máxima libertad que sea posible para que consiga su auto-perfeccionamiento. Para ello, el individualismo defiende que son necesarios dos elementos, a saber: la libertad económica y la propiedad privada. El mercado libre es la única forma no coercitiva de coordinar un mercado complejo.

Una cuestión muy importante es la ser propietario de tu propia persona. De esta manera se puede utilizar como sea conveniente las habilidades y fuerza de trabajo. Si esto no sucede así, se acaba siendo propiedad de otro y respondiendo a sus fines como, por ejemplo, en la esclavitud o en un Estado socialista donde se responde a los fines de la comunidad. Si no tienes libertad sobre tu cuerpo, no puedes establecer libremente tus objetivos. Se trata de algo esencial para poder ser un individuo libre. La libre competencia no es un conjunto de suposiciones, sino unas «reglas» que conducen a la mayor satisfacción, y la impersonalidad del mercado implica igualitarismo, ya que tendrá éxito una persona en función de su esfuerzo, habilidad, mérito y/o suerte, pero sin discriminación.

\section{BETTY FRIEDAN}

Desde el punto de vista del feminismo liberal, se entiende que la situación penosa en la que viven las mujeres en comparación con los hombres se debe a una desigualdad legal (evitando así el uso de términos tales como «explotación», «opresión»...). Las claves para estas feministas liberales son dos, a saber: el ámbito público, y el campo laboral. Es necesario que las mujeres formen parte importante de estas dos áreas para que su situación de desigualdad pase a convertirse en igualdad. Precisamente por ello, 
se centraron en la importancia de la formación, de la cultura en las mujeres. Si pretenden que éstas aspiren a tener cargos de poder en los partidos políticos, en las empresas...el primer requisito que deben cumplir es el de estar capacitadas para desarrollar las funciones que dichos cargos necesitan. Pero pronto se dieron cuenta de lo importante que era tener derecho a la propiedad privada para el movimiento. Sin este derecho, no se podía avanzar. Por eso, se pusieron a recoger firmas para que las mujeres pudieran mantener sus propiedades después del matrimonio.

Betty Friedan es una psicóloga social que entiende que la situación en la que viven las mujeres se debe a la existencia de un marco legal que es necesario modificar para mejorar la calidad de vida de todas las personas, no sólo de las mujeres. Le apasionaba la justicia y el derecho, pero no lo estudió porque en aquella época no admitían a mujeres en esa facultad (idea de la importancia del derecho y la justicia también presentes en la Escuela Austriaca).

La autora fue una de las fundadoras del $\mathrm{NOW}^{6}$ (Organización Nacional para las Mujeres), agrupación feminista que nació en 1966, y su primera Presidenta. B. Friedan es clave en el nuevo feminismo de la época, preocupándose tanto en lo teórico de su pensamiento como de la parte más práctica.

Había mujeres jóvenes en los movimientos estudiantiles de izquierdas pero estaban cabreadas porque sus compañeros no las tomaban en serio, y se limitaban a prepararles la comida y a realizar otras labores de este estilo. Friedan quería incluirlas en el NOW, al igual que quería contar con las monjas católicas, con la League of Women Voters, con los del SNCC, con las amas de casa ${ }^{7} . .$. Eran todas muy diferentes pero estaban unidas, ya que su objetivo no tenía que ver con valores políticos, sino la consecución de una causa: mejorar la calidad de vida de todas las personas.

${ }^{6}$ Una de las propuestas del NOW era la de bajar los impuestos a la unidad familiar.

7 En el NOW había radicales, seguramente provenientes del comunismo. Y solían hablar de la redistribución de la riqueza y ese tipo de temas. No obstante, Friedan no era partidaria de incluir en el movimiento de mujeres esos debates ya que son ajenos a él. 
Las feministas de izquierdas criticaban a las mujeres de la clase alta que estaban en el movimiento, pero Friedan siempre afirmaba que tienen que estar si pretendían un movimiento que no excluya a ninguna mujer para que sea eficiente, para que las represente a todas. Como escribe la propia autora: «para mí el movimiento de mujeres siempre ha formado parte de una profunda revolución de los roles definidos en función del sexo; no se trataba de mujeres contra hombres, sino mujeres y hombres desechando los roles obsoletos establecidos en función del sexo que nos impedían ser lo que todos podíamos ser» (Friedan, 2003, pp. 258259).

Friedan simpatizó en sus años de juventud con el comunismo por sus ganas de sentirse en un grupo de iguales (tuvo una infancia dura respecto a la cuestión de la amistad), pero tampoco se sintió nunca llena en ese movimiento ya que sus compañeras revolucionarias la criticaban llamándola «señoritinga». Así que, ni se encontraba bien tampoco con las personas comunistas ni le gustaba su prosa. Ni el Partido Comunista ni el marxismo se preocupaban de explicar la situación de las mujeres. Con palabras de la propia autora: «el comunismo cada vez me convencía menos» (Friedan, 2003, p. 93).

En la universidad estudió lo malo que era el capitalismo, porque coartaba la libertad de la ciudadanía, y lo bueno que era el comunismo, ya que defendía la tolerancia, el respeto, la libertad, la igualdad... Pero la realidad le mostró otra cosa. En los sitios comunistas trataban mal a los judíos...y en los capitalistas había manifestaciones, libertad de expresión, etc. De hecho, se alegraba enormemente de vivir en Norteamérica y no en uno de esos países comunistas donde, la realidad, mostraba cómo los pensadores no tenían libertad ni buenas condiciones de vida materiales. De hecho, destaca que, cuando trabajaba en un periódico sindical, le despidieron por quedarse embarazada, diciéndole que era su culpa por quedarse embarazada de nuevo. ¿Y ellos eran los que iban a defender los derechos de los más débiles? De todos modos, no le vino mal este despido, ya que se sentía mal en el trabajo por dos motivos: ya no tenía los mismos ideales (cada vez era menos comunista), y no la trataban como uno más por ser mujer. Daba igual lo buenos que fueran sus artículos. Por otro 
lado, también destaca el peligro de los «ismos» ya que pueden desembocar en autoritarismo. ${ }^{8}$

Dos obras fundamentales de la autora son La mística de la feminidad, publicada en 1963, y La segunda fase, editada en el año 1981.

El contexto en el que se ha de situar La mística de la feminidad, es la postguerra de la Segunda Guerra Mundial. A pesar de la fuerza que había caracterizado al movimiento feminista los años anteriores, después de la Segunda Guerra Mundial hubo un receso que es analizado por Friedan en dicha obra.

La autora escribe La mística de la feminidad, donde analiza el contexto de las mujeres norteamericanas después de la Segunda Guerra Mundial. Éstas, se glorificaban de su papel de amas de casa siguiendo el consejo de la mística de la feminidad de que el valor más alto y la única misión de las mujeres es la realización de su propia feminidad y dedicación al hogar. Esto desembocó, primeramente, en una falsa felicidad y, más tarde, en un sinfín de problemas psicológicos en las mujeres. Se trataba de un problema de personalidad que no se soluciona con responder a la pregunta «¿quién soy yo?» respondiendo «¿la madre de Juan», «la mujer de Tomás»...?

Poco antes de que esta mística de la feminidad se adueñase de las mujeres norteamericanas, había habido una guerra, después una depresión económica y todo fulminó con la bomba atómica. Todo el mundo se sentía vulnerable, nostálgico, solitario...

Esa sensación de malestar que tenían las mujeres encerradas en sus hogares y que intentaban enmendar con el alcohol, el activismo en la asociación de padres o con pastillas recetadas por médicos (todos estos caminos insuficientes para solventar la cuestión) fue denominada por Friedan como «el problema que no tiene nombre». Para solucionarlo, propone dejar de seguir las pautas de la mística de la feminidad y desarrollar la personalidad, formarse, trabajar...aunque todas estas actividades conlleven un enorme esfuerzo. Pero ni las teorías de Freud (que tanto estaban de moda), ni las de Marx (de las que se vanagloriaban los

8 Para más información sobre el peligro de los «ismos» leer «New isms endangering liberty» de Gerhard Schwarz (versión española publicada en Procesos de Mercado, n. ${ }^{\circ}$ 10, vol. 1, primavera 2013). 
comunistas) eran capaces de explicar este «problema que no tiene nombre».

En La segunda fase, trata los temas relacionados con la doble jornada, con los nuevos criterios que debe tomar el feminismo para no quedarse obsoleto... Analiza los resultados de la lucha feminista y propone mejoras para que se sigan consiguiendo sus objetivos. La primera fase consistía en conseguir participación real en los partidos políticos y las empresas norteamericanas. Pero, si se quiere avanzar con la misma velocidad, deben plantearse algunas cuestiones. En la primera fase, parecía que había que elegir, por ejemplo, entre la vida laboral y la familiar. Pero, lo que hace falta es ir más allá de la ideología, de las viejas maneras de pensamiento y pasar así a la segunda fase.

Además, la autora demuestra que la liberación de las mujeres va a implicar consecuencias positivas también para los hombres, los cuales van a ser más libres. Por lo tanto, lo más beneficioso es otorgar libertad... a las mujeres de la misma manera que la tienen los hombres para que exista un mejor nivel de vida en toda la humanidad. Es decir, entiende el feminismo como una teoría que conlleva un carácter civilizatorio.

Ahora bien, el movimiento liberal español tuvo una gran diferencia con respecto al de otros Estados como Gran Bretaña, Estados Unidos... a saber: mientras en éstos últimos lugares las mujeres pudieron ejercer un derecho tan básico como lo es el del voto por medio de años de luchas sociales, en España se consiguió a través de la actividad política, ${ }^{9}$ gracias a la labor, fundamentalmente, de Clara Campoamor. Serían dignas de mención las siguientes líneas: «del voto femenino puede decirse que gozaba de la más absoluta impopularidad entre la mayoría de los varones; nadie creía llegado el momento de la equidad para la mujer. Algunos llegaron a afirmar que la concesión ni siquiera interesaba

9 Normalmente se tiende a pensar que la primera vez que se consiguió el derecho al voto femenino en España fue en la II República, pero no es así. La primera vez que las mujeres pudieron votar fue durante la Dictadura de Primo de Rivera, el problema es que era un derecho muy restrictivo que permitía a muy pocas mujeres el voto. En la II República se amplió hasta igualar el criterio al derecho al voto masculino. 
a las mujeres. El entusiasmo con que éstas lo han ejercitado después es la respuesta a esa hipótesis, una más, lanzada alegremente en la eterna y vanidosa explicación de la mujer, que el hombre se ha arrojado siempre la facultad de interpretar» (Campoamor, 2010, p. 183).

Caben destacar, sobre todo, dos obras de Campoamor, a saber: el voto femenino y yo: mi gran pecado y la revolución española vista por una republicana. La primera obra muestra lo complicado que le resultó la aprobación del voto de las mujeres en la Segunda República y las consecuencias personales que le ocasionó (expulsión de su partido político). Basta una lectura de esta obra para comprender que el movimiento sufragista feminista no entiende de ideales políticos («la maniobra estaba clara. Los republicanos tenían miedo a la juventud, tenían miedo a la mujer (los distinguió siempre el miedo a todo)», (Campoamor, 2010, p. 156). La segunda obra que se menciona, la revolución española vista por una republicana, expone también los errores que cometió el bando de la izquierda durante la Guerra Civil Española. La autora no duda en desvelar los hechos que se han intentado ocultar durante mucho tiempo y en criticarlos, provengan del bando que provengan. Tal vez sería positivo destacar unas líneas de esta obra: «La división tan sencilla como falaz hecha por el Gobierno entre fascistas y demócratas, para estimular al pueblo, no se corresponde con la verdad» (Campoamor, 2001, p. 75).

Llegados a este punto, se destacarán tres citas de Betty Friedan:

Lo irónico es que las feministas entonces, como ahora, no sacaron sus ideas de los comunistas. Los comunistas mismos no incluían el trabajo de la mujer en su concepto de la organización del proletariado industrial (Friedan, 1983, p. 269).

El comunismo, concretamente la línea estalinista-leninista, hizo caso omiso del trabajo que realizaba la mitad de la especie humana, hizo caso omiso del trabajo doméstico no retribuido de la mujer, y tenía en cuenta solamente el trabajo industrial del hombre (Friedan, 1983, p. 270).

Debemos servirnos del sistema capitalista para hacer frente a las nuevas necesidades de crecimiento individual y familiar (Friedan, 1983, p. 291). 
Betty Friedan define la tarea del movimiento feminista como:

Romper la discriminación sexual en el trabajo, las profesiones, la educación y la Iglesia; al conquistar para la mujer cierta medida de independencia económica y de dignidad que tan desesperadamente necesitaban, control sobre sus propios cuerpos y sobre el proceso reproductor, y una sencilla y digna protección policial contra la violación (Friedan, 1983, p. 51).

Según esto, podemos entender que, al menos en teoría, el feminismo es perfectamente compatible con la teoría liberal.

Además, defiende que los hombres son parte muy importante en la segunda fase del feminismo. Quieren vivir con la misma libertad que las mujeres. Libertad para poder expresar sus sentimientos y verse realizados en las dos esferas, campos de la vida, la laboral y la familiar. Otro claro ejemplo de que sigue teniendo en cuenta la autora más la eficiencia que otros aspectos $\mathrm{y}$, por lo tanto, continúa con una postura de feminista liberal, es cuando afirma que el feminismo debe llevar a cabo su lucha mediante el método beta (el estilo Beta, es concebido como femenino, y se basa en un pensamiento sintetizador, intuitivo, cualitativo, que contextúa las cosas y las relaciona. Se preocupa por la totalidad del problema. Es compatible con los cambios) y no el alfa (el estilo Alfa, considerado como más masculino, se basa en un método de pensamiento analítico, racional y cuantitativo. Sus ideas fundamentales son las de la autoridad. Es un estilo directo y agresivo. No es compatible con los cambios) o cuando escribe que en la lucha del aborto es mejor cambiar la argumentación y en lugar de hablar de derecho a abortar se hable del derecho a elegir tener hijos. Para Friedan la maternidad es un valor, pero no así el aborto. No obstante, sería injusto que el Estado lo prohibiera utilizando todo el poder de su fuerza coactiva. ${ }^{10}$

10 Como podemos leer también en La ética de la libertad de Rothbard, donde el autor desarrolla extensamente los argumentos de por qué debe ser el aborto legal en una sociedad libertaria, extrapolables a cualquier sociedad libre, en el sentido de que el Estado no debe inmiscuirse en las decisiones individuales ni encarcelar a una madre por decidir abortar pues su papel, en caso de existir, debe limitarse al mínimo necesario para mantener y hacer posible el proceso de cooperación social; una cosa es 
Por otro lado, a través de la siguiente cita la autora enlaza el feminismo con el liberalismo y el individualismo:

...El feminismo constituye una amenaza para los déspotas del fascismo, el comunismo y el fundamentalismo religioso, tanto en su variedad tercermundista como norteamericana, por ser un experimento en individualismo, en autonomía humana, en libertad personal, que, una vez completamente sentido, es imposible de borrar o controlar (Friedan, 1983, p. 296).

En esta cita Friedan utiliza el término «autonomía», un clásico en Kant, también liberal. Cuando deja de ser primordial la libertad personal, individual, se afirman frases como la de Hitler en Mein Kampf: «el derecho a la libertad personal retrocede ante del deber de conservar la raza...el sacrificio de la existencia personal es necesario para garantizar la conservación de la especie» (Friedan, 1983, p. 292). Es decir, nunca hay que subestimar las claves del individualismo y sus principios filosóficos. Y Friedan se acercaría a Hayek y al neoliberalismo en cierto sentido en cuanto a su opinión sobre la ley y la mayoría. La grandeza de la democracia es que lo que hoy es defendido por una minoría mañana puede serlo por la mayoría. Según Hayek, un gobierno no está legitimado porque haya sido elegido por la mayoría, sino porque respete siempre unas normas adecuadas. No es que a Hayek no le importe la mayoría, sino que quiere limitar su importancia en base a su ideal de sometimiento a la ley. Y, por eso mismo, quien pone en tela de juicio los consensos es el más inteligente. No se trata de aceptar sin más lo que dice la mayoría, puesto que la mayoría puede estar equivocada, como ha ocurrido en muchísimos acontecimientos históricos.

Pero se dan más ocasiones en las que Friedan se posiciona de parte del liberalismo, como cuando afirma que las mujeres deben competir en tanto que individuos y no en cuanto a su sexo, ni para lo bueno ni para lo malo. Por tanto, desecharía la intervención del Estado y su ayuda a los grupos desfavorecidos. Tanto desde la perspectiva de Betty Friedan como de la de Hayek, aunque existen

la (obvia) inmoralidad del aborto, y otra bien distinta que el Estado deba existir o esté legitimado para prohibirlo por la fuerza. 
diferencias entre la gente, estas diferencias no se han de tener en cuenta. Es decir, no es necesario dar un paso de la diferencia a la desigualdad. Pero no sólo eso, sino que continúa hablando de individualismo y, con sus palabras, el individualista parece todo un feminista al escribir que: «la ideología individualista contiene la creencia de que el hombre y la mujer son ambos seres humanos únicos, no teniendo ninguno de ellos ninguna predilección o propensión natural al cuidado del hogar, al cuidado de los hijos o al trabajo retribuido. Las tareas de la vida en familia se dividen según las necesidades específicas y las preferencias de cada individuo. Las parejas desean tener hijos por la experiencia que supone el ser padres, y las reformas familiares que «aumentan las opciones de la gente» son bien recibidas» (Friedan, 1983, p. 200).

De esta manera Friedan muestra cómo se pueden defender algunos ideales del liberalismo, como los que conlleva el individualismo, dentro de la teoría feminista. Aquí, se encontraría otro punto común con Hayek, puesto que separa muy bien el liberalismo de la derecha y de la izquierda. Es decir, para ambos autores, son tres ideologías diferentes. Aunque también muestra una actitud conciliadora entre el liberalismo y la derecha, al decir que las cuestiones sobre la igualdad son una necesidad, a escala personal y política, que nadie, ni conservador ni liberal, puede pasar ya por alto. Afirma que los nuevos problemas a los que se enfrentan requieren algo más que la polaridad izquierda-derecha, que no se va a encontrar la solución en ninguno de los dos pensamientos porque los dos contienen errores importantes, sino que hay que apostar por el liberalismo. Los problemas no se van a solucionar ni con el programa político de la derecha ni con el comunista. $Y$ es que, el comunismo ignoró el trabajo que realiza el cincuenta por ciento de la humanidad y que no es retribuido, esto es, el trabajo de las mujeres en el hogar. No se preocupó de la equidad en el trabajo doméstico entre los dos sexos... Una idea importante que resalta la autora es que como el comunismo carecía de feminismo, fue más negativo que el capitalismo. Ya que, al menos, egoístamente, el capitalismo, de alguna manera, se preocupaba por las mujeres ya que eran consumidoras y tenían que tenerlas en cuenta, cosa que no ocurrió en el comunismo. Pero, por otro lado, también recrimina el hecho de tener que elegir entre feminismo 
y familia, algo que se inventó la derecha para dañar al feminismo, y que el feminismo se equivocó al seguir los pasos de esa polarización. Con la creación de nuevos tipos de familia, la familia es completamente compatible con el feminismo. Pero no sólo eso, sino que lo refuerza y mejora la vida de las mujeres, que no pueden encontrar todo en el mundo laboral. Es decir, Friedan concibe a la teoría feminista más allá de valores políticos de izquierdas o derechas. Lo entiende como un movimiento con unos objetivos concretos cuya consecución es una tarea de máxima importancia, por lo que lo que cobra más protagonismo son los resultados obtenidos. De esta manera, quedan claros sus argumentos de eficacia política.

Un punto muy importante que tendrían en común el feminismo de Betty Friedan con la Escuela Austriaca es el siguiente, a saber: Friedan se posicionó a favor de la ERA. ${ }^{11} \mathrm{Y}$ la apoyaba porque comprendió que las medidas protectoras son negativas para quienes, precisamente, quieren proteger. Por ejemplo, era muy perjudicial limitar las horas de trabajo en las mujeres, aunque fuera con la intención de mirar por su salud. Y era negativo debido a tres motivos: uno, las aleja de los mejores puestos de trabajo, dos, porque obliga a los hombres a trabajar más horas para mantener a su familia, y tres, puesto que impide a las mujeres mantener a su familia. Se imposibilita, así, que puedan ganar más haciendo horas extras... ${ }^{12}$. Además, la ERA otorgaba a las mujeres el derecho a poseer propiedades, otro de los motivos por los que Friedan la apoyaba. No obstante, los sindicatos se posicionaron en contra de la ERA.

Otra conclusión, en esta misma línea, a la que llega Friedan después de un profundo estudio, es que la gente que se dedica a profesiones que no tienen establecida una edad de jubilación obligatoria es la gente que vive más años (artistas, directores de orquesta, jueces del Tribunal Supremo...). Es decir, que no debería existir una edad de jubilación obligatoria marcada por el Estado.

\footnotetext{
11 Enmienda para asegurar la igualdad a la hora de aplicar las leyes entre los hombres y las mujeres norteamericanas, en todas las circunstancias.

12 Es como establecer un salario mínimo a los trabajadores. Lo único que se consigue es generar más paro en los sectores de la población más vulnerables: mujeres, jóvenes, mayores, inmigrantes, gente sin formación...
} 
Para finalizar, se destacará otra acción que llevó a cabo Betty Friedan en la dirección ya comentada de la importancia de la propiedad privada y de las consecuencias nefastas de vivir en un sistema intervenido por el Estado. Friedan creó el First Women's Bank and Trust Company (Primer Banco de Crédito de Mujeres), ya que a las mujeres norteamericanas no les daban los bancos los créditos únicamente en función de su sexo. Ni se paraban a estudiar el negocio para el que necesitaban la financiación. Esto en un capitalismo real ${ }^{13}$ no ocurriría, ya que el banco analizaría objetivamente la capacidad de devolución de la deuda y se basarían únicamente en eso para conceder el crédito o no).

Antes de terminar con el artículo, se mencionará rápidamente en qué consiste el feminismo radical, para poder juzgar si la teoría de Friedan, finalmente, debe converger en él.

Es preciso explicar el significado de «feminismo radical». En este caso, «radical» no proviene de «extremo», sino de «raíz». Es decir, estas feministas entienden que para solucionar los problemas de las mujeres es necesario ir a la raíz del problema mismo, porque solamente suprimiendo la causa que los provocan se borraran definitivamente las consecuencias de éstos. No sirve de nada actuar sobre las consecuencias directamente. Entienden que la situación en la que viven las mujeres es debido a un sistema, el patriarcado. Por ello, como hay que acudir a la raíz del problema, se proponen analizar a fondo su significado y abolirlo.

En Política sexual, obra fundamental en esta corriente escrita por Kate Millett, se entiende el término «política» como poder, como la relación en la que unas personas mandan, y otras obedecen (no se piensa desde la perspectiva tan cerrada de pensar la política únicamente vinculada a los partidos políticos...). Una de las tesis de dicha obra es que el sexo no es ajeno a la política.

Para estas feministas, el patriarcado es un sistema de dominación en el que no sólo es que los hombres dominen a las mujeres, sino también que los hombres mayores dominan a los hombres más pequeños. Pero este patriarcado se manifiesta de múltiples

13 A pesar de lo que se suele comentar en los debates políticos, no nos encontramos inmersos en el sistema capitalista, sino en un sistema altamente intervenido por el Estado y los Bancos Centrales. 
maneras. Es necesario tener en cuenta la diferencia que existe en un patriarcado de $\mathrm{X}$ momento histórico y situación geográfica con otro. Por ejemplo, es muy distinto el patriarcado de Arabia Saudí que el americano. Para el patriarcado, la clave está en justificar las diferencias biológicamente porque, de este modo, estaría el ser humano coordinado con la naturaleza. Sin embargo, no hay argumentos lo suficientemente bien desarrollados como para justificar dicha idea. Por ejemplo, la fuerza física que se supone mayor en los hombres que en las mujeres, no es sólo por motivos biológicos, sino por costumbres, ya que desde bien pequeños, practican más deporte que las mujeres. Además, aunque reconociéramos la mayor fuerza de los hombres por naturaleza, esto es completamente insignificante en las relaciones políticas. Con conocimiento, técnica o con un arma una persona débil pasa a ser la más fuerte. Las diferencias que encontramos entre los sexos se deben, pues, más a motivos culturales que a biológicos.

VI

REFLEXIONES FINALES

En el mercado se trata a todos los seres humanos con la máxima igualdad. El capital divide a la sociedad en dos grupos: los que poseen más y los que poseen menos. Pero esta división está por encima de la raza, el sexo... además, permite a los ciudadanos/as el cambio de un grupo a otro debido a su esfuerzo, habilidad y/o suerte. En este sentido, parece un sistema muy justo al dar la oportunidad a todos de mejorar su situación vital.

En un sistema en el que el Estado interviene y lleva a cabo una redistribución de las riquezas por grupos según él crea conveniente, puede ser que beneficie a las mujeres pero, también, que las perjudique (imaginemos dicha acción, por ejemplo, en Arabia Saudí). Por tanto, parece que lo más justo es que sea el mercado mismo el que se encargue de repartir beneficios en función únicamente de unas cuentas, e independientemente de si se es mujer, negro, chino... además, es una manera de fomentar el esfuerzo de la gente, lo cual generaría una mayor evolución de todo el género humano. Es decir, si se obtiene lo que se merece 
de una manera justa y ofrecen la oportunidad de conseguirlo, una gran parte de la gente se esforzará en mayor medida, mientras que si se reparte desde un Estado paternalista, se generara conformismo y estancamiento. Para demostrar esto con datos reales, está el testimonio de B. Friedan, que quería ampliar el significado de feminismo y estudió como había evolucionado el feminismo en los países socialistas, como Finlandia, Suecia y Checoslovaquia. Viajó allí y escribió: «una vez más, sufrí una decepción» (Friedan, 2003, p. 265).

Por lo tanto, se puede entender el sistema capitalista de libre mercado compatible con la idea de igualdad, con establecer criterios universales a la hora de juzgar las decisiones que se toman. De hecho, parece que el libre mercado es el único sistema que permite una libertad real en la ciudadanía, aspecto clave también en la teoría feminista. De esta manera, sí cabría pensar una teoría feminista compatible con el liberalismo económico.

Por otra parte, B. Friedan, a lo largo de toda su obra, mantiene una actitud de eficacia política, típica del feminismo liberal y, además, en ningún momento deja de lado el individualismo. Todo esto sugiere que la autora no deja de lado el feminismo liberal para pasar a ser una feminista radical. Friedan no renuncia a su primer feminismo, sino que de lo que se percata es que es necesario que se adecue a las nuevas circunstancias para que se vuelva más efectivo.

De esta manera, queda clara la no necesidad de traspaso de un feminismo liberal a otro radical.

Además, habría que recordar los cuatro argumentos de la Escuela Austriaca a partir de los cuales demuestran la imposibilidad del socialismo. Desde esta perspectiva, todas las corrientes del pensamiento deberían posicionarse al lado del libre mercado y, por ende, en contra del socialismo si no quieren que las mismas críticas recaigan sobre sus teorías.

No obstante, no es suficiente con lo que escribe Mises para defender la economía de libre mercado. Lo que se necesita es ampliar las miras de lo económico a una ética objetiva, que podría ser la feminista. Se podría denominar «feminismo austriaco» $\mathrm{o}$, incluso, haciendo honor tanto a los verdaderos orígenes de los principios de la Escuela Austriaca como a la idea de este artículo, «feminismo austriaco-español», que haría hincapié en 
la importancia de la libertad y rechace cualquier atisbo de estatismo e igualitarismo. ${ }^{14}$

Para el libertario conseguir la libertad es el objetivo más importante. Como no se anteponga la libertad a cualquier otra meta total nunca se llegará a ella.

La libertad es un principio moral intrínsecamente unido a la propia naturaleza del ser humano. Se basa en la justicia y elimina la violencia. «El libertario debe sentir auténtica pasión por la justicia, una emoción derivada de y canalizada por su percepción de lo que la justicia natural exige» (Rothbard, 1995, p. 347) (recordemos que este mismo sentimiento estaba presente en B. Friedan). Y, como la libertad es el objetivo más importante en la política, las herramientas para alcanzarlas deben ser las más eficaces. La rapidez es un valor a tener en cuenta.

Pero, como tanto el tiempo como la fuerza de cada persona son limitados, se puede priorizar en las actividades en cuanto a la búsqueda de una sociedad libertaria. Por eso esta propuesta se basa en la «reconciliación» de la sociedad libertaria con la feminista. Querer la libertad se asienta en un deseo moral por la justicia que se debe conseguir cuanto antes.

El mundo lo mueven las ideas. Por ello es muy importante expandir el ideario del libertarismo para que triunfe en todos los grupos de la sociedad (incluso, en el feminista). Por eso la educación es tan importante, porque es necesaria para llegar a la libertad. Las ideas se transmiten a través de la gente, no por sí mismas. Por ello, para que la libertad se implante debe existir un grupo de activos libertarios cuyo objetivo primordial sea ese. Tiene que ser gente muy bien formada en el campo de la libertad y que difunda este mensaje. Es decir, debe existir un movimiento libertario. Tiene que haber profesionales que se dediquen a esta causa. Por ejemplo, si no hubiera sido por los médicos profesionales no habría avanzado tanto la medicina. Para que avance la medicina es imprescindible que exista la profesión de médico. El desarrollo de la libertad tiene que ser una profesión (pero profesionales no subvencionados desde los gobiernos, porque de lo contrario, se

${ }^{14}$ La igualdad que persigue el feminismo se refiere a la aplicación igualitaria de la ley, la justicia y el derecho. 
sufriría el problema que vivió el movimiento feminista: que no podían hacer mucho ruido por miedo a perder el puesto de trabajo).

Las nuevas ideas surgen en una persona o en unas pocas y luego se difunden al resto de personas que se encuentran de acuerdo. Los libertarios son una vanguardia teóricamente minoritaria que, esperemos, se vuelva mayoritaria.

$Y$ es que, en cuanto al futuro, cabe ser optimistas. Por un lado, los Estados son los que llevan los últimos años gobernando entre múltiples escándalos políticos y económicos dirigiendo a su ciudadanía, además, a la crisis en la que se encuentra inmersa. Por otro lado, la sociedad cada vez aboga más por la industrialización y, para ello, se necesita libertad. Pero tampoco se puede olvidar la experiencia vivida en los países comunistas, donde la planificación estatal ha resultado ser catastrófica para sus ciudadanos/as. Además, cuanta mayor libertad económica y mejores condiciones de vida existan para todas las personas, mejor se conseguirá el objetivo feminista de aumentar la calidad de vida de todos y todas. Betty Friedan escribe que en uno de sus viajes a países comunistas (Nicaragua en 1984) los marxistas le dijeron que se preocupaban tanto por las mujeres, que les habían dado máquinas de coser para mejorar sus vidas, cuando lo que necesitaban de verdad era formación. Hay que defender otro tipo de sociedad más justa.

\section{REFERENCIAS BIBLIOGRÁFICAS}

Amorós, C. y Miguel, A. (2005): Teoría feminista: de la Ilustración a la globalización. Volumen III: «De los debates sobre el género al multiculturalismo», Minerva ediciones, Madrid.

BeAuvoir, S. (1975): El segundo sexo, Ediciones Siglo Veinte, Buenos Aires.

BÖHMLER, A. (1998): El ideal cultural del liberalismo, Unión Editorial, Madrid.

CAMPOAMOR, C. (2001): El voto femenino y yo: mi gran pecado, Horas y horas, Madrid.

- (2001): La revolución española vista por una republicana, Madrid (s.n), 2000. 
Fagoaga, C. y SAavedra, P. (2008): Clara Campoamor: la sufragista española, Instituto de la Mujer, Madrid.

Friedan, B. (1974): La mística de la feminidad, Editorial Júcar, Madrid.

- (1983): La segunda fase, Editorial Plaza y Janés, Barcelona.

- (2003): Mi vida hasta ahora, Ediciones Cátedra, Madrid.

Gray, J. (1992): Liberalismo, Nueva Imagen, México.

HAYeK, F.A. von (2001): Principios de un orden social liberal, Unión Editorial, Madrid.

- (2009): Individualismo: el verdadero y el falso, Unión Editorial, Madrid.

- (2010): Hayek sobre Hayek (un diálogo autobiográfico), Unión Editorial, Madrid.

- (1982): Los fundamentos de la libertad, Unión Editorial, Madrid.

Huerta de Soto, J. (2006): Dinero, crédito bancario y ciclos económicos, Unión Editorial, Madrid.

- (2000): La Escuela Austriaca. Mercado y creatividad empresarial, Editorial Síntesis, Madrid.

- (sin fecha): conferencia «La crisis del socialismo», Faes.

LuKES, S. (1975): El individualismo, Ediciones Península, Barcelona.

MACPHERSON, C.B. (1991): La democracia liberal y su época, Alianza Editorial, Madrid.

Muñoz, J. (2003): Diccionario Espasa de Filosofía, Espasa, Madrid.

ORTEGa y Gasset, J. (1937): La rebelión de las masas, Alianza Editorial, México.

Perona, A.J. (1993): Entre el liberalismo y la socialdemocracia, Popper y la «sociedad abierta», Anthropos, Editorial del Hombre, Barcelona.

- (2005): Teoría feminista: de la Ilustración a la globalización. Volumen 2: del feminismo liberal a la posmodernidad, Minerva Ediciones, Madrid.

Popper, K. (1996): La miseria del historicismo, Alianza, Madrid.

- (1984): La sociedad abierta y sus enemigos, Orbis, Barcelona.

RAND, A. (2005): El manantial, Grito Sagrado, Buenos Aires.

RöPKe, W. (2010): La crisis social de nuestro tiempo, El Buey Mudo, Madrid.

RothbaRd, M. (1995): La ética de la libertad, Unión Editorial, Madrid.

SChWARZ, G. (2012): New isms endangering liberty, Praga. 